\title{
Antioxidant Potential of Selected Underutilized Fruit Crop Species Grown in Sri Lanka
}

\author{
M.A.L.N. Mallawaarachchi, W.M.T. Madhujith ${ }^{1 *}$ and D.K.N.G. Pushpakumara ${ }^{2}$
}

\author{
Postgraduate Institute of Agriculture \\ University of Peradeniya \\ Sri Lanka
}

\begin{abstract}
Lyophilized aqueous extracts of four underutilized fruit species namely Diospyros discolor (Velvet apple), Pouteria campechiana (Lavulu/Canistel), Phylanthus acidus (Mal-Nelli/Star gooseberry) and Phyllanthus emblica (Nelli/Indian gooseberry) were investigated for the antioxidant potential (AP) by 2,2-diphenyl-1-picrylhydrazyl (DPPH) assay, 2,2-azino-bis-3-ethylbenzothiazoline-6-sulphonic acid (ABTS) assay and ferrous reducing antioxidant power (FRAP) assay. Total phenolic content (TPC) and total monomeric anthocyanin content (TMAC) were determined by Folin-Ciocalteu's colorimetric assay and $\mathrm{pH}$ differential method, respectively. Vitamin $\mathrm{C}(\mathrm{VitC})$ content of fresh fruit was evaluated titrimertically and expressed as mg of ascorbic acid in $100 \mathrm{~g}$ of fresh weight (FW). The TPC and TMAC were expressed as $\mathrm{mg}$ of gallic acid equivalents (GAE)/100g FW and $\mathrm{mg}$ of cyanodin-3-glucoside (C3G)/100g FW. The measured parameters differed significantly among four fruit species. The values ranged between $84.42-1939.70 \mathrm{mg} \mathrm{GAE} / 100 \mathrm{~g} \mathrm{FW}, 10.41-$ $55.64 \mathrm{mg} \mathrm{C} 3 \mathrm{G} / 100 \mathrm{~g} \mathrm{FW}, 0.067$ - $310.63 \mathrm{mg} \mathrm{FW} / \mathrm{ml}, 9$ - 81.29\%, 238.25 - 2891.57 $\mathrm{Fe}^{2+} \mu \mathrm{mol} / 100 \mathrm{~g} \mathrm{FW}$ and $17.12-523.14 \mathrm{mg} / 100 \mathrm{~g} \mathrm{FW}$ for TPC, TMAC, IC ${ }_{50}$, RSA, FRAP and VitC, respectively. Phyllanthus emblica possessed highest values in all parameters while Phyllanthus acidus showed the lowest except in TPC. The lowest TPC was observed in Diospyros discolor. The extract of Pouteria campechiana also showed considerable amount of TPC (640 mg C3G/100g FW), RSA (76\%) and VitC of $53 \mathrm{mg} / 100 \mathrm{~g}$. The results revealed that these underutilized fruit crops can be used as sources of natural antioxidants and vitamin C.
\end{abstract}

Keywords: Antioxidant potential, total anthocyanin content, total phenolic content, underutilized fruits crop species, Vitamin C

\section{INTRODUCTION}

Reactive oxygen species (ROS) are considered as harmful intermediates produced during oxygen metabolism in biological systems. Excess ROS in the body can lead to cumulative damage in proteins, lipids, and DNA, resulting in the condition termed as oxidative stress (Dudonne et al., 2009). Antioxidants can effectively mitigate the oxidative damage in biological systems by delaying or inhibiting the oxidation process caused by ROS (Shofian $e t$ al., 2011). Numerous epidemiological studies have reported that the regular consumption of fruits and vegetables is associated with the reduction of chronic diseases which are directly

1 Department of Food science and Technology, Faculty of Agriculture, University of Peradeniya, Sri Lanka

2 Department of Crop science, Faculty of Agriculture, University of Peradeniya, Sri Lanka

* Corresponding author: madujith@yahoo.com 
linked with the oxidative stress. The increased intake of natural antioxidants, particularly the antioxidative compounds present in fruits and vegetables contribute to the antioxidant capacity of plasma and these constituents are reported to mitigate the damage caused by the oxidative stress (Lie et al., 2005; Oviasogie et al., 2009; Vidhan et al., 2010; Bopitiya and Madhujith, 2012).

In nutritional sciences and medicine, there is much interest on analysis of vitamins such as $\mathrm{C}$, $\mathrm{E}$ and $\mathrm{A}$ as they are widely reported to have antioxidant activities via multiple mechanisms (Rutkowski and Grzegorczyk, 2007). Vitamin C, reduces the risk of arteriosclerosis, cardiovascular diseases and some forms of cancer (Jacob, 1996; Lee and Kader, 2000). Vitamin $\mathrm{C}$ is also known to have many biological functions in collagen formation, absorption of inorganic iron, reduction of plasma cholesterol level, inhibition of nitrosoamine formation, enhancement of the immune system and reaction with singlet oxygen and other free radicals (Lee and Kader, 2000). Both vitamin A and E are lipid soluble. Vitamin A is important for normal vision, growth, ageing and reproduction (Adeolu and Enesi, 2013). Vitamin E considered as a chain breaking antioxidant and reported that regular intakes are correlated with a reduced risk of cardiovascular diseases (Flome and Traber, 1999) Therefore, these plant extracts can be used as potential candidates to isolate natural antioxidants. Wide varieties of fruit crop species are available in Sri Lanka. Besides major fruit crops, there is a large number of fruit species that remain underutilized. As a result, their nutritive, medicinal and therapeutic values are little known to date.

The commonly grown two members of the family Euphorbiaceae, namely Phyllanthus emblica L. (Nelli/Indian gooseberry) and Phyllanthus acidus L. (Rata-Nelli/Star gooseberry) are cultivated as backyard fruit species in Sri Lanka. The fruits of $P$. emblica eaten in fresh form are considered as highly nutritious and therapeutic due to its high amount of Vitamin $\mathrm{C}$, antioxidant and polyphenol content (Pushpakumara and Heenkenda 2007). It is reported to use in prevention and management of haemorrhage, anaemia, colic, acute leprosy, fits, insanity, jaundice, cough, hiccough, indigestion, dyspepsia, asthma and other diseases in traditional medicine (Jayaweera, 1981). P. acidus fruits may be eaten fresh after sprinkled with salt, processed into pickle and sweetened dried fruits. In Malaysia, ripe and unripe fruits are cooked and served as a relish, or made into a thick syrup or sweet preserve (Lim, 2012a). Ramasamy et al. (2011) reported that leaves of $P$. acidus perform mild cytotoxicity on human breast cancer cell line (MCF7), epidermal carcinoma of cervix cell line (CaSki), ovarian cancer cell line (KO3) and colon cancer cell line (HT29). However, these fruit crops have been neglected in Sri Lanka and their uses have not been properly exploited (Pushpakumara and Heenkenda 2007).

Pouteria campechiana (Kunth) Baehni. (Sapotaceae), Canistel locally known as Lavulu mainly grown in home gardens of wet and intermediate zones of Sri Lanka. Due to its compact crown and glossy leaves, the tree is used for landscaping as well. The fruit is consumed as a dessert fruit or pickled with salt and pepper. The dehydrated pulp can be used as natural food colorant especially in baked products. Lanerolle et al. (2008) reported that P. campechiana fruit pulp is a rich source of pro-vitamin A carotenoids.

Diospyros discolor Willd. a member of family Ebenaceae commonly known as velvet apple, normally grown in the home gardens of wet and intermediate zones of Sri Lanka as ornamental and road side shade tree. It has been reported that fruits, leaves and bark of $D$. discolor is used in traditional medicine to cure diarrhoea, cough, fever and dysentery. The ripe fruit is peeled and eaten fresh or used in salad or stew or fried like a vegetable (Lim, 2012b). According to Lee et al. (2006) the leaves of $D$. discolor possesses higher antioxidant activity. However to 
the best of our knowledge, there are no previous reports on antioxidant potential of $P$. campechiana and D. discolor fruit.

Present study was carried out to evaluate the antioxidant potential, total phenolic, total anthocyanin and vitamin C contents of four underutilized fruit crop species namely, Phyllanthus acidus, Phyllanthus emblica, Pouteria campechiana and Diospyros discolor.

\section{METHODOLOGY}

\section{Chemicals and regents}

The gallic acid, Folin-Ciocalteu's phenol reagent, sodium carbonate, 2,2-azinobis (3ethylbenzothiazoline-6-sulfonic acid) diammonium salt (ABTS), 2,2-Azobis (2amidinopropane) dihydrochloride (AAPH), 2,2-diphenyl-1-picrylhydrazyl hydrate (DPPH), 2, 4, 6-tris (2-pyridyl)-1, 3, 5-triazine (TPTZ) and 2,6-dichlorophenolindophenol, were purchased from Sigma, USA. All other chemicals used were of analytical grade.

\section{Sample preparation}

Fully matured fruits of $P$. acidus (Star gooseberry), P. emblica (Indian gooseberry) and fully ripe fruits of $P$. campechiana (Canistel) and D. discolor (Velvet apple) (Figure 1) were collected from the plants at mid fruiting stage from the home gardens in the Bandarawela region belonging to the upcountry intermediate zone (IU3), Sri Lanka and transported to the Regional Agriculture Research and Development Centre, Bandarawela under cold conditions. The samples were sorted for physical and pest damages, washed with running tap water followed by distilled water and drained to remove the surface water. Hundred grams of each fruit was taken after removing seeds and outer skin of $P$. campechiana and $D$. discolor. Then homogenized to prepare the composite sample. Six samples from each fruit were used to prepare the composite sample. For the evaluation of total phenolic content total monomeric anthocyanin content and antioxidant potential, $40 \mathrm{~g}$ of homogenates of each species were extracted with $120 \mathrm{ml}$ of distilled water by keeping on reciprocating shaker at $450 \mathrm{rpm}$ for 90 $\mathrm{min}$ at room temperature followed by centrifugation at $4,500 \mathrm{rpm}$ for $10 \mathrm{~min}$. The supernatants were collected separately and the extraction was repeated twice with residues, supernatants were combined and lyophilized at $-50{ }^{\circ} \mathrm{C}, 24$ mbar for $96 \mathrm{~h}$ and subsequently stored at $-20{ }^{\circ} \mathrm{C}$ until further analysis.

To determine total phenolic content (TPC), ferric reducing antioxidant power (FRAP), total antioxidant capacity (TAC) and total monomeric anthocyanin content (TMAC), twenty milligrams of each lyophilized samples were dissolved in $3 \mathrm{ml}$ of methanol, filtered using whatman number one filter papers, the filtrates were volume up in the $5 \mathrm{ml}$ volumetric flasks with distilled water to have final concentration of $4 \mathrm{mg} / \mathrm{ml}$. For the DPPH assay, $50 \mathrm{mg}$ of lyophilized samples were taken followed same procedure then six different concentrations ranging between $0.5 \mathrm{mg} / \mathrm{ml}$ and $10 \mathrm{mg} / \mathrm{ml}$ were prepared.

\section{Determination of total phenolic content}

The TPC was measured using the method described by Yu et al. (2002) with slight modifications. Briefly, $100 \mu \mathrm{l}$ of $2 \mathrm{~N}$ Folin-Ciocalteu regent and $1.58 \mathrm{ml}$ of distilled water were added to $20 \mu \mathrm{l}$ of each sample, vortexed, incubated at room temperature for 8 minutes, subsequently $300 \mu \mathrm{l}$ of $0.7 \mathrm{M}$ sodium carbonate was added, incubated for 30 minutes at room 
temperature, and absorbance was measured at $765 \mathrm{~nm}$ by using a Helios Omega - UV - VIS spectrophotometer. Different concentrations of gallic acid $(0-1 \mathrm{mg} / \mathrm{ml})$ were used to construct the standard curve and the results were expressed as mg gallic acid equivalents in $100 \mathrm{~g}$ of fruit in fresh weight (mg GAE/100 $\mathrm{g} \mathrm{FW}$ ).
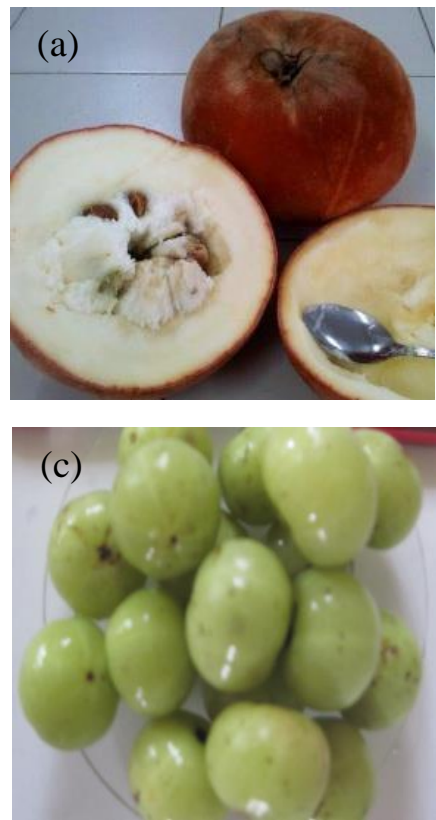
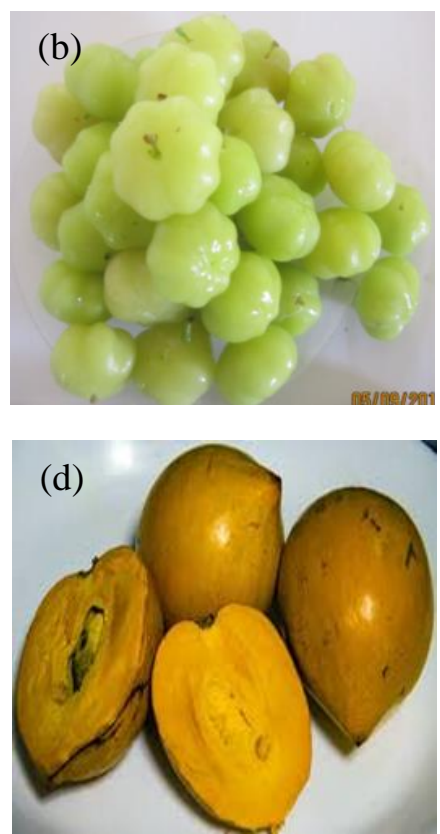

Figure 1. Fruits of Selected Species (a - D. discolor fruit, b-P. acidus fruit, c-P. emblica fruit, and d - P. campechiana fruit)

\section{Determination of antioxidant potential}

\section{Ferric reducing antioxidant power assay}

The assay was adapted from Benzie and Strain (1996) with minor changes. The FRAPreagent was freshly prepared by mixing acetate buffer ( $150 \mathrm{mM}, \mathrm{pH} 3.6)$, TPTZ solution (5 mM TPTZ in $40 \mathrm{mM} \mathrm{HCl}), \mathrm{FeCl}_{3} 6 \mathrm{H}_{2} \mathrm{O}(10 \mathrm{mM})$ in a ratio of $10: 1: 1$. The regent was pre-heated at $37^{\circ} \mathrm{C}$ in a water bath for $10 \mathrm{~min}$. To perform the assay, $1.5 \mathrm{ml}$ of FRAP reagent and $0.05 \mathrm{ml}$ sample $(4 \mathrm{mg} / \mathrm{ml})$ were mixed and vortexed for $30 \mathrm{~s}$, absorbance was measured at $593 \mathrm{~nm}$, using the FRAP working solution as a blank after a lapse of $4 \mathrm{~min}$. The antioxidant potential of samples were determined using a linear regression equation $\left(\mathrm{Y}=6.723 \mathrm{x}, \mathrm{r}^{2}=0.9389\right)$ obtained from the standard curve plotted using $\mathrm{FeSO}_{4} 7 \mathrm{H}_{2} \mathrm{O}(0-5 \mathrm{mM})$ and results were expressed as $\mu \mathrm{M}$ of $\mathrm{Fe}$ ${ }^{2+} / 100 \mathrm{~g}$ fruits in fresh weight $(\mathrm{FW})$.

\section{DPPH radical scavenging assay}

The 2, 2-diphenyl-1-picrylhydrazyl hydrate (DPPH) free radical scavenging activity of fruit crop species was carried out according to the method described by Su et al. (2007) with some modifications. Six different concentrations ranged between $0.5 \mathrm{mg} / \mathrm{ml}$ and $10 \mathrm{mg} / \mathrm{ml}$ of each lyophilized extract $(0.2 \mathrm{ml})$ was mixed with $1.8 \mathrm{ml}$ of $0.1 \mathrm{mM}$ methanolic DPPH radical. The absorbance was read at $517 \mathrm{~nm}$ using Helios Omega - UV - VIS spectrophotometer after 
leaving the mixture for an hour in the dark at room temperature. The procedure was repeated six times for each concentration. The control was prepared by adding $0.2 \mathrm{ml}$ of methanol into $1.8 \mathrm{ml}$ of DPPH radical. Using following formula, the radical scavenging activity (RSA) was calculated as percentage of discoloration of DPPH radical.

$$
\operatorname{RSA} \%=\left\{1-\left(\mathrm{A}_{\text {sample }} / \mathrm{A}_{\text {control }}\right)\right\} * 100
$$

where; $\mathrm{A}_{\text {sample }}$ is the absorbance of the sample at $517 \mathrm{~nm}$ and $\mathrm{A}_{\text {control }}$ is the absorbance of the control at $517 \mathrm{~nm}$.

The results were expressed as $\mathrm{IC}_{50}$ values that denote the concentration of the sample required (mg of $\mathrm{FW} / \mathrm{ml}$ ) to scavenge $50 \%$ of DPPH radicals, was derived from RSA vs Concentration plot of each sample.

\section{Determination of total antioxidant capacity}

The TAC was determined using ABTS radical scavenging capacity assay. The ABTS radical cation $\left(\mathrm{ABTS}^{\cdot+}\right.$ ) was generated by reacting 2,2- azino-bis (2-ethylbenzothiazoline-6-sulfonic acid) diammonium salt (ABTS, $2.5 \mathrm{mM}$ in PBS at $\mathrm{pH}$ 7.4) with 2,2'- azino-bis (2methylpropanimidamide) dihydrochloride (AAPH, $2 \mathrm{mM}$ in PBS at $\mathrm{pH} 7.4$ ) in to 1: 1 ratio. The mixture was kept in a water bath at $60{ }^{\circ} \mathrm{C}$ until color developed which possess the absorbance between $0.3-0.5$ at $734 \mathrm{~nm}$. To $40 \mu \mathrm{l}$ of each sample, $1.96 \mathrm{ml}$ of stock was added and absorbance was measured over six minutes at one minute interval at $734 \mathrm{~nm}$ (Zhou and $\mathrm{Yu}, 2004)$, the RSA was calculated as percentage inhibition of $\mathrm{ABTS}^{\bullet+}$ radical.

\section{Determination of total monomeric anthocyanin content}

The pH differential method, previously reported by Lee et al. (2005) was used with slight modifications to determine the total monomeric anthocyanin content of the freeze dried extracts. In brief, two separate reaction medium were prepared with $1.80 \mathrm{ml}$ of, potassium chloride buffer ( $\mathrm{pH} \mathrm{1})$ and sodium acetate buffer $(\mathrm{pH} \mathrm{4.5)}$ with $0.2 \mathrm{ml}$ of extract $(4 \mathrm{mg} / \mathrm{ml})$ for each. Reaction medium was kept for $15 \mathrm{~min}$ at room temperature followed by absorbance was measured at $520 \mathrm{~nm}$ and $700 \mathrm{~nm}$ wave lengths using Helios Omega - UV - VIS spectrophotometer. The TMAC was calculated as follows and expressed as mg of Cyanidin3-glucoside in $100 \mathrm{~g}$ of Fresh sample.

\begin{tabular}{|c|c|c|c|}
\hline & & & A $x$ MW $x$ DF $\times 10^{3}$ \\
\hline & $\csc$ & & $\mathcal{E} \times 1$ \\
\hline A & $=$ & Absorbanc & $\left.520-\mathrm{A}_{700}\right)_{\mathrm{pH} 1}-\left(\mathrm{A}_{520}-\mathrm{A}_{700}\right) \mathrm{pH} 4.5$ \\
\hline MW & $=$ & Molecular & ht C3G (449.2g) \\
\hline DF & $=$ & Dilution fa & \\
\hline 1 & $=$ & Path length & \\
\hline$\theta$ & $=$ & Molar extir & co-efficient (26 900) \\
\hline
\end{tabular}

\section{Determination of the vitamin $\mathrm{C}$ content}

Determination of vitamin C content was performed on the basis of content of L- Ascorbic acid (AA), by using the titrimetric method described by Omale and Ugwu (2011). Accurately weighed $(5 \mathrm{~g})$ of fresh sample was macerated with $0.25 \%$ Oxalic acid solution, filtered, filtrate 
was transferred to a $50 \mathrm{ml}$ volumetric flask volume up to the mark with $0.25 \%$ oxalic acid and $10 \mathrm{ml}$ of it taken for the titration with standardized 2,6 Dichlorophenolindophenol dye solution.

\section{Statistical analysis}

Data, obtained by six replicates were statistically analyzed using SAS 9.1 statistical software. Analysis of variance and least significant difference tests were conducted to identify mean differences. Statistical significance was declared at $p=0.05$. To evaluate the relationship between methods used, linear regression and correlation analysis of the values were performed using MS Office Excel software.

\section{RESULTS AND DISCUSSION}

\section{Total phenolic content}

Polyphenolic compounds are commonly found in both edible and inedible plants, and reported to have multiple biological effects, including antioxidant activity (Kähkönen et al., 1999; Wojdylo et al., 2007). The TPC of selected fruit species was evaluated by Folin-ciocaltures' colorimetric method, varied widely among selected fruit species ranging from $84.42 \mathrm{mg}$ GAE/100 FW in $D$. discolor to $1,939.70 \mathrm{mg}$ GAE/100 g FW in $P$. emblica (Table 1). All aqueous extracts tested, contained high TPC compared to commonly consumed fruit species. The TPC of pineapple, mango, papaya, apple, and berries were 47.9, 56.0, 57.6, 11.9, and 28.7 mg GAE/100g, respectively (Kriengsak et al., 2006; Bopitiya and Madhujith 2012). While Silva and Sirasa (2018) reported 80\% (v/v) methanolic extracts of TPC of P. emblica was $915.7 \mathrm{mg} \mathrm{GAE} / 100 \mathrm{~g} \mathrm{FW}$, which was lower than that of our results. The water extracts of $P$. emblica prepared by boiling for $5 \mathrm{~min}$, reported to have $295.94 \mathrm{mg}$ GAE/g of dry weight (Jayathilake et al., 2016). The methanolic extracts of different parts (bark, fruits and leaves) of D. discolor reported to contain $9.16,5.95$ and $5.65 \mathrm{mg} \mathrm{GAE} / \mathrm{g}$ of extract, respectively (Das et al., 2010). Ethanolic extracts of oven dried fruits of $P$. acidus are reported to have $4.26 \mathrm{mg}$ GAE/g (Zulaikha et al., 2017). It was found that the yield in total phenolic compounds depends on the method and the choice of solvent (Goli et al., 2005). The TPC also varies with the growing season, soil and climatic factors, stage of maturity of the plants (Wang and Zheng, 2001).

\section{Total monomeric anthocyanin content}

Anthocyanins considered as one of the major bioactive compounds among six classes of flavonoids (flavonols, flavanones, isoflavones, flavan-3-ois, flavones and anthocyanins) (Haminuik et al., 2012). There is increasing interest in the anthocyanin content of food and neutraceuticals because of possible health benefits (Lee et al., 2005). In this study, pH differential method was adapted to measure TMAC and calculations were done based on the cyaniding-3-glucoside (C3G), results were expressed as $\mathrm{C} 3 \mathrm{G}$ equivalents in $\mathrm{mg} / 100 \mathrm{~g} \mathrm{FW}$. According to the results presented in Table 1, the highest (55.64 mg C3G/ $100 \mathrm{~g} \mathrm{FW}$ ) TMAC was observed in P. emblica followed by P. campechiana, D. discolor and P. acidus. To the best of our knowledge this is the first report of TMAC of these fruit species in Sri Lanka.

\section{Vitamin $C$ content (Vit $C)$}

The vitamin C content was expressed as mg of ascorbic acid (AA) in $100 \mathrm{~g}$ of fruits in fresh weight. The results summarized in Table 1 , revealed that $P$. emblica had the highest AA and 
P. acidus had the lowest. The value for the AA of P. emblica (523.14 mg AA/100 g FW) was differed with the observation of Silva and Sirasa (2018). Lee and Kader, 2000 stated that nutritional composition of a fruit type at harvest can vary widely depending on cultivar, maturity, climate, soil type, and fertility.

Vitamin C (AA) is an important dietary antioxidant in humans; it acts as highly effective antioxidant (Padayatty et al., 2003). In view of its antioxidant property, ascorbic acid and its derivatives are widely used as preservatives in food industry. Ascorbic acid plays an important role in the maintenance of collagen, which represents about one third of the total body protein.

Table 1. Total Phenolic Content (TPC), Total monomeric anthocyanin content (TMAC) and Vitamin $C$ content (VitC) of selected fruit species

\begin{tabular}{lrrr}
\hline Fruit Species & \multicolumn{1}{c}{ TPC } & \multicolumn{1}{c}{ TMAC } & \multicolumn{1}{c}{ VitC } \\
\hline P. emblica & $1,939.70 \pm 0.81^{\mathrm{a}}$ & $55.64 \pm 13.79^{\mathrm{a}}$ & $523.14 \pm 2.24^{\mathrm{a}}$ \\
P. campechina & $640.01 \pm 0.48^{\mathrm{b}}$ & $29.68 \pm 4.33^{\mathrm{b}}$ & $53.03 \pm 1.04^{\mathrm{b}}$ \\
P. acidus & $112.89 \pm 0.26^{\mathrm{c}}$ & $10.41 \pm 3.59^{\mathrm{c}}$ & $17.12 \pm 0.76^{\mathrm{d}}$ \\
D. discolor & $84.42 \pm 0.09^{\mathrm{d}}$ & $13.14 \pm 3.29^{\mathrm{c}}$ & $39.15 \pm 0.78^{\mathrm{c}}$ \\
\hline
\end{tabular}

Data are presented as Mean $\pm \mathrm{SD}(\mathrm{n}=6)$

Values with different letters are significantly different at $\mathrm{p}<0.5$

TPC - mg GAE/100g fruit in fresh weight (FW), TMAC - mg C3G/100g fruit in FW and VitC - mg AA/100g fruits in FW

\section{Antioxidant potential of fruit extracts}

Antioxidant potential (AP) of plant extracts can be evaluated by using ability of scavenging of free radicals, as they deactivated or stabilized by the antioxidants before they cause oxidative damage towards cellular structures (Lee et al., 2014). Therefore, AP of lyophilized water extracts were determined by their ability to scavenge $\mathrm{DPPH}^{*}$ and $\mathrm{ABTS}^{\cdot+}$ radicals and reducing power of Ferric to Ferrous using three different assays of DPPH, ABTS and FRAP respectively. In DPPH, results were expressed as concentration $(\mathrm{mg} / \mathrm{ml})$ of fresh sample needed for inhibit $50 \%$ of radicals $\left(\mathrm{IC}_{50}\right.$ value) in the reaction medium, which was obtained from the graphs developed from RSA values of different concentrations of each sample $(0.5-$ $10 \mathrm{mg} / \mathrm{ml}$ ) and higher $\mathrm{IC}_{50}$ values denote lower AP. The $\mathrm{IC}_{50 \mathrm{~b}}$ values of four extracts ranged from 0.067 to $310.63 \mathrm{mg} \mathrm{FW} / \mathrm{ml}$. According to the $\mathrm{IC}_{50} \mathrm{~b}$ values presented in the Table 2 , the highest AP was obtained in P. emblica followed by P. acidus, P. campechiana and D. discolor. According to the $\mathrm{IC}_{50}$ value of less than $1 \mathrm{mg} / \mathrm{ml}$ is categorized as a fruit with extremely high antioxidant potential (Safaa et al., 2010, Bopitiya and Madhujith, 2012). Therefore, P. Emblica fruits can be categorized as extremely high antioxidative fruits. In ABTS assay, results are presented as RSA values, which denote the percentage of inhibiting of $\mathrm{ABTS}^{-+}$by the individual sample $(4 \mathrm{mg} / \mathrm{ml})$ over six minutes. As described in the Figure 2, among the selected fruit extracts, the highest total antioxidant capacity being observed in $P$. emblica $(81.29 \%)$, while least was recorded in $P$. acidus (9\%). The extracts of $D$. discolor and $P$. campechiana were also possessed considerably higher RSA values of $71.17 \%$ and $76.14 \%$, respectively. But interestingly within first minute of the reaction, more than $50 \%$ of the ABTS cation radical was inhibit by the fruit extract of $P$. emblica and $D$. discolor and completed the reaction within four minutes. In contrast, $P$. acidus started to react with $\mathrm{ABTS}^{-+}$after first minute and showed very slow reaction rate, finally reached to $9 \%$ of RSA within six minutes. Nevertheless, the 
extracts of P. campechiana initially showed slow activity, reached the second highest RSA value of $76.14 \%$ after six minutes.

Table 2. DPPH, ABTS Radical Scavenging Activity and FRAP of Fruit Extracts

\begin{tabular}{lrrrr}
\hline \multirow{2}{*}{ Fruit species } & \multicolumn{2}{c}{$\begin{array}{c}\text { DPPH Radical Scavenging } \\
\text { Activity }\end{array}$} & \multirow{2}{*}{$\begin{array}{c}\text { ABTS } \\
\text { RSA\% }\end{array}$} & \multirow{2}{*}{ FRAP Value } \\
\cline { 2 - 3 } & \multicolumn{1}{c}{ IC $_{\mathbf{5 0} \text { a }}$} & \multicolumn{1}{c}{$\mathbf{I C}_{\mathbf{5 0} \mathrm{b}}$} & & \\
\hline P. emblica & $0.01 \pm 0.00^{\mathrm{d}}$ & $0.067 \pm 0.00^{\mathrm{c}}$ & $81.29 \pm 2.42^{\mathrm{a}}$ & $2,891.57 \pm 4.95^{\mathrm{a}}$ \\
P. campechina & $8.97 \pm 0.25^{\mathrm{a}}$ & $130.49 \pm 3.64^{\mathrm{b}}$ & $76.14 \pm 0.16^{\mathrm{b}}$ & $1,941.54 \pm$ \\
D. discolor & $7.19 \pm 0.11^{\mathrm{b}}$ & $310.63 \pm 4.74^{\mathrm{a}}$ & $71.17 \pm 0.42^{\mathrm{c}}$ & $16.44^{\mathrm{b}}$ \\
P. acidus & $5.60 \pm 0.40^{\mathrm{c}}$ & $124.14 \pm 8.84^{\mathrm{b}}$ & $9.00 \pm 0.48^{\mathrm{d}}$ & $405.35 \pm 19.10^{\mathrm{c}}$ \\
& & & & $238.25 \pm 56.05^{\mathrm{d}}$ \\
\hline
\end{tabular}

Data are presented as Mean $\pm \mathrm{SD}(n=6)$

Values with different letters are significantly different at $\mathrm{p}<0.5$

RSA - lyophilized sample of $4 \mathrm{mg} / \mathrm{ml}$ (over six minutes), FRAP - $\mu \mathrm{M}$ of $\mathrm{Fe}^{2+} / 100 \mathrm{~g}$ of fruit in fresh weight, IC $50 \mathrm{a}$ $\mathrm{mg}$ of lyophilized sample/ml, IC $50 \mathrm{~b}-\mathrm{mg}$ of fruit in fresh weight $/ \mathrm{ml}$

The FRAP assay was carried out to investigate the ability of selected fruit extracts to reduce ferric ion $\left(\mathrm{Fe}^{3+}\right)$ to ferrous ion $\left(\mathrm{Fe}^{2+}\right)$. It quantifies the reducing power of extract which is an integral attribute of such compounds (Bopitiya and Madhujith, 2012). The highest and lowest reducing powers were observed in $P$. emblica and $P$. acidus, respectively. The extracts of $P$. campechiana also showed higher reducing property with $1,941.54 \mathrm{Fe}^{2+} \mu \mathrm{M} / 100 \mathrm{~g} \mathrm{FW}$ (Table 2). In this study both P. emblica and P. campechiana fruit extracts showed higher reducing power than the commonly consumed fruits such as mango and banana as observed by Silva and Sirasa (2018).

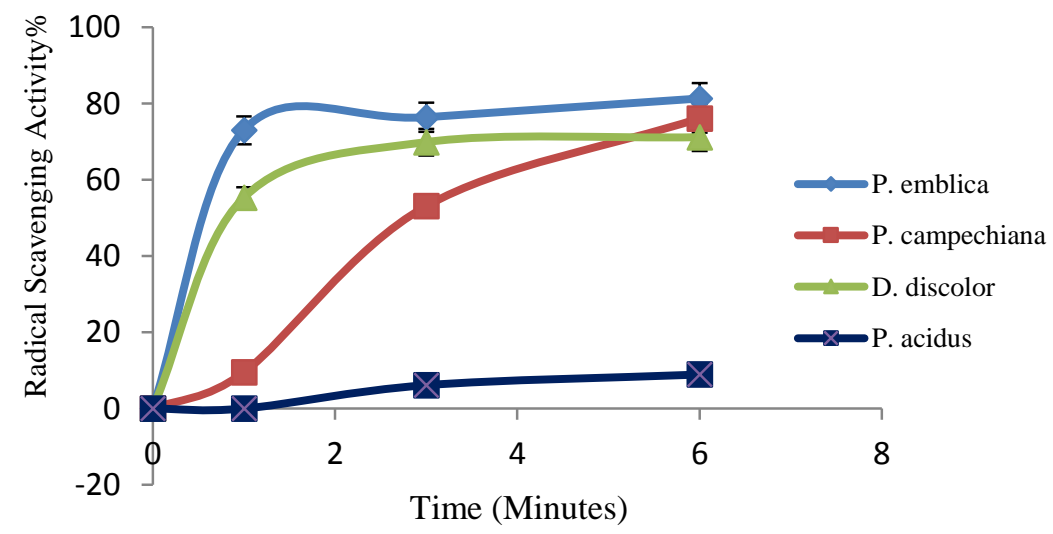

Figure 2. ABTS $^{\bullet+}$ radical scavenging activity of fruit crop species

Use of a single method to determine antioxidant capacity is insufficient, thus adoption of different assays and model systems provide a better insight into the actual activity of the extracts (Bopitiya and Madhujith, 2012). The results summarized in the Table 2, illustrates antioxidant potential of selected fruit extracts are significant at $\mathrm{p}=0.05$ except in $\mathrm{IC}_{50}$ in $\mathrm{FW}$ basis. It may be due to different extraction yield of individual fruit species. Based on the results, $P$. emblica exhibited the highest TPC, TMAC, VitC and AP. 


\section{Correlation analysis}

The Table 3 illustrates the correlation between tested parameters with $\mathrm{R}^{2}$ values. The DPPH, FRAP, ABTS, TMAC and VitC showed strong positive correlation with TPC. The least correlation, but positive $\left(\mathrm{R}^{2}=0.0009\right)$ was observed between DPPH and ABTS assays, while other four methods performed were possessed more than $0.5 \mathrm{R}^{2}$ values. This poor correlation may be due to different attributes of phenolic compounds. Also the reaction time of the ABTS assay is only six minutes much shorter than that of DPPH (Surveswaran et al., 2007).

Table 3. Correlation between TPC, DPPH, ABTS, FRAP, TMAC and VitC

\begin{tabular}{lrrrrr}
\hline $\mathbf{R}^{2}$ & \multicolumn{1}{l}{ TPC } & \multicolumn{1}{l}{ DPPH } & FRAP & ABTS & TMAC \\
\hline TPC & - & - & - & - & - \\
DPPH & 0.6509 & - & - & - & - \\
FRAP & 0.8803 & 0.5591 & - & - & - \\
ABTS & 0.9500 & 0.0009 & 0.4691 & - & - \\
TMAC & 0.9784 & 0.5889 & 0.9533 & 0.4120 & - \\
VitC & 0.9384 & 0.5989 & 0.6781 & 0.1811 & 0.8533 \\
\hline
\end{tabular}

\section{CONCLUSIONS}

The results revealed that water extracts of the fruit crops tested have potential antioxidant activity and vitamin $\mathrm{C}$ content. The extract of $\mathrm{P}$. emlica exhibited significantly higher antioxidant potential, vitamin C, TPC and TMAC than other fruit crops. This study highlighted significance of selected underutilized fruit species as cheap sources of natural antioxidants and Vitamin C. Further studies to identify individual phenolic compounds and also in vivo studies to understand their mechanism of action are therefore suggested.

\section{ACKNOLEDGEMENT}

The authors acknowledge Postgraduate Institute of Agriculture, University of Peradeniya for their financial support through Research Facilitation Fund (RFF).

\section{REFERENCES}

Adeolu, A.T. and Enesi, D.O. (2013). Assessment of proximate, mineral, vitamin and phytochemical composition of plantain (Musa paradisiaca) bract - an agricultural waste. Int. J. Plant Sci. 4(7), 192-197.

Benzie, I.F.F. and Strain, J.J. (1996). Ferric reducing ability of plasma (FRAP) as a measure of "antioxidant power": the FRAP assay. Anal. Bio-chem. 239(1), 70-76.

Bopitiya, D. and Madhujith, T. (2012). Antioxidant potential of pomegranate (Punica granatum L.) cultivars grown in Sri Lanka. Trop. Agric. Res. 24(1), 71-81. 
Das, S.C., Hamid, K., Bulbul, I.J., Sultana S. and Islam, S. (2010). In Vitro Antioxidant Activity of Different Parts of the Plant Diospyros discolor. Res. J. of Agric. and Biol. Sci. 6(4), 472-475.

Dudonne S., Vitrac, X., Coutiere, P., Woillez, M. and Merillon, J.M. (2009). Comparative study of antioxidant properties and total phenolic content of 30 plant extracts of Industrial interest using DPPH, ABTS, FRAP, SOD and ORAC assays. J. Agric. Food Chem. 57(5), 1768-1774.

Flohe, R.B and Traber M.G. (1999). Vitamin E: function and metabolism. The FASEB J. 13, $1145-1155$.

Goli, A.H, Barzegar, M. and Sahari, M.A. (2005). Antioxidant activity and total phenolic compounds of pistachio (Pistachia vera) hull extracts. Food Chem. 92, 521-525.

Haminiuk, C.W.I., Maciel, G.M., Plata-Oviedo, M.S.V. and Peralta, R.M. (2012). Invited review Phenolic compounds in fruits - an overview. Int. J. Food Sci. and Tech. 47(10), 20232044.

Jacob, A.R. (1996). Chapter 01: Introduction. pp. 1-16. In Harris, J.R. (Ed.) Subcellular Biochemistry, Ascorbic Acid: Biochemistry and Biomedical Cell Biology, vol. 25. Plenum, New York, NY, USA.

Jayathilake, C., Rizliya, V. and Liyanage, R. (2016). Antioxidant and free radical scavenging capacity of extensively used medicinal plants in Sri Lanka. Procedia Food Sci. 6, 123-126.

Jayaweera, D.M.A. (1981). Medicinal plants (Indigenous and exotic) used in Ceylon. Part II. The National Science Foundation, Sri Lanka. pp. 228-229.

Kahkonen, M. P., Hopia, A. I., Vuorela, H. J., Rauha, J.-P., Pihlaja, K., Kujala, T. S. (1999). Antioxidant activity of plant extracts containing phenolic compounds. J. Agri. and Food Chem. 47, 3954-3962.

Kriengsak, T., Unaroj, B., Kevin, C., Luis, C. and David, H.B. (2006). Comparison of ABTS, $\mathrm{DPPH}, \mathrm{FRAP}$, and ORAC assays for estimating antioxidant activity from guava fruit extracts. J. Food Com. and Analysis. 19, 669-675.

Lanerolle, M.S.De, Priyadharshani, A.M.B., sumithraarachchi, D.B. and Jansz E.R. (2008). The carotenoids of Pouteria campechiana (Sinhala: ratalawalu). J. of the National. Science Foundation, Sri Lanka. 36(1), 95-98.

Lee, S.K. and Kader, A.A. (2000). Preharvest and postharvest factors influencing vitamin C content of horticultural crops. Postharvest Bio. and Tech. 20, 20-220.

Lee, J., Robert, W.D. and Ronald, E.W. (2005). Determination of total monomeric anthocyanin pigment content of fruit juices, beverages, natural colorants, and wines by the $\mathrm{pH}$ differential method: collaborative study. J. AOAC Int. 88(5), 1269-1278. 
Lee, M.H., Jiang, C.B., Juan, S.H., Lin, R.D. and Hou, W.C. (2006). Antioxidant and heme oxygenase-1 (HO-1)-induced effects of selected Taiwanese plants. Fitoterapia. 77(2), 109115.

Lee, S., Mediani, A., Nur Ashikin, A., Azliana, A. and Abas, F. (2014). Antioxidant and $\alpha-$ glucosidase inhibitory activities of the leaf and stem of selected traditional medicinal plants. Int. Food Res. J. 21(1), 165-172.

Lie-Fen, S., Jieh-Hen, T., Je-Hsin, C., Chih-Yang, C. and Chiu-Ping, L. (2005). Antioxidant properties of extracts from medicinal plants popularly used in Taiwan. Int. J. Applied Sci. and Eng. 3(3), 195 - 202.

Lim, T.K. (2012a). Phyllanthaceae: Phyllanthus acidus in Edible Medicinal and non-medicinal plants, Vol 4, Fruits, Springer Science+Business Media. London, pp. 252- 257.

Lim, T.K. (2012b). Ebinaceae: Diospyros blancoi in Edible Medicinal and non-medicinal plants, Vol 2, Fruits, Springer Science+Business Media. London, UK. pp. 421-424.

Omale J. and Ugwu C. E. (2011). Comparative studies on the protein and mineral composition of some selected Nigerian vegetables. African J. Food Sci. 5(1), 22-25.

Oviasogie, P.O., Okoro, D. and Ndiokwere, C.L. (2009). Determination of total phenolic amounts of some edible fruits and vegetables. African J. Biotech. 8(12), 2819 -2820.

Padayatty, S., Katz, A., Wang,Y., Eck, P., Lee, J., Chen, S., Corpe, C., Dutta, A., Dutta, S. and Levine, M. (2003). Vitamin C as an antioxidant: evaluation of its role in disease prevention. J. Am. Clin. Nutr. 22(1), 18-35.

Pushpakumara, D.K.N.G. and Heenkenda, H.M.S. (2007). Chapter 06: Nelli (Amla) (Phyllanthus embilica L.). pp. 180-221. In Pushpakumara, D.K.N.G., Gunasena, H.P.M., Singh, V.P. (Ed.) Underutilized Fruit Trees in Sri Lanka Volume 1. World Agro-forestry Centre, South Asia Regional office, New Delhi, India; National Multipurpose Tree Species Research Network of Sri Lanka; Sri Lanka Council for Agricultural Research Policy, Asian Centre for Underutilized Crops, Sri Lanka.

Ramasamy, S., Wahab, N.A., Abidin, N.Z. and Manickam, S. (2011). Cytotoxicity evaluation of five Malaysian Phyllanthaceae species on various human cancer cell lines. J. Med. Plant Res. 5(11), 2267-2273 .

Safaa, Y. Q., Abo-khatwa, A.N. and Lahwa, M.A.B. (2010). Screening of antioxidant activity and phenolic content of selected food items cited in the Holly Quran. Europ. J. Biol. Sci. 2(1), 40-51.

Shofian, N.M., Hamid, A.A., Osman, A., Saari, N., Anwar, F., Dek, M. S. P. and Hairuddin, M.R. (2011). Effect of freeze-drying on the antioxidant compounds and antioxidant activity of selected tropical fruits. Int. J. Mol. Sci. 12, 4678-4692.

Silva, K.D.R.R. and Sirasa M.S.F. (2018). Antioxidant properties of selected fruit cultivars grown in Sri Lanka. Food Chem. 238, 203-208. 
Su, L., Yin, J.J., Charles, D., Zhou, K., Moore, J. and Yu, L. (2007). Total Phenolic contents, chelating capacities and radical-scavenging properties of black peppercorn, nutmeg, hrosewhip, cinnamon and oregano leaf. J. Food Chem. 100(3), 990-997.

Surveswaran, S., Cai, Y.Z., Cork, H. and Sun, M. (2007). Evaluation of natural phenolic antioxidant from 133 Indian medicinal plants. Food Chem. 102, 938-953.

Vidhan, J., DerMarderosian, A. and John, R.P. (2010). Anthocyanins and polyphenol oxidase from dried arils of pomegranate (Punica granatum L.). J. Food Chem. 118(1), 11-16.

Wang, S.Y and Zheng, W. (2001). Effect of plant growth temperature on antioxidant capacity in strawberry, J. Agric. Food Chem. 49, 4977-4982.

Wojdyło, A., Oszmianski, J. and Czemerys R. (2007). Antioxidant activity and phenolic compounds in 32 selected herbs. Food Chem. 105, 940-949.

Yu, L., Perret, J. and Davy, B., Wilson, J. and Melby, C.L. (2002). Antioxidant properties of cereal products. J. Food Sci. 67(7), 2600-2603.

Zhou, K. and Yu, L. (2004). Antioxidant properties of bean extracts from Trego wheat grown at different locations. J. Agri. Food Chem. 52(5), 1112-1117.

Zulaikha, A.G.S., Mediani, A., Khoo, L.W., Lee, S.Y., Leong, S.W. and Abas, F. (2017). Effect of different drying methods and solvent ratios on biological activities of Phyllanthus acidus extracts. Int. Food Res. J. 24(1), 114-120. 